04,06

\title{
Тонкая структура импедансных спектров кристаллов с пьезоэлектрическим эффектом
}

\author{
(C) В.Г. Гофрфман ${ }^{1}$, М.Е. Компан ${ }^{2}$, А.В. Гороховский ${ }^{1}$, Н.В. Горшков ${ }^{1}$, \\ А.В. Байняшев ${ }^{1}$, О.С. Телегина ${ }^{1}$, В.И. Воронкова ${ }^{3}$, И.Н. Антонов ${ }^{1}$, Ю.В. Агапова ${ }^{1}$ \\ ${ }^{1}$ Саратовский государственный технический университет им. Ю.А. Гагарина, \\ Саратов, Россия \\ ${ }^{2}$ Физико-технический институт им. А.Ф.Иоффре, \\ Санкт-Петербург, Россия \\ ${ }^{3}$ Московский государственный университет им. М.В. Ломоносова, \\ Москва, Россия \\ E-mail: vggoff@mail.ru
}

(Поступила в Редакцию 23 октября 2018 г.)

На примере кристалла KDP в импедансных спектрах с высоким разрешением было обнаружено и интерпретировано проявление пьезоэлектрических резонансов. У кристаллов $\mathrm{LiIO}_{3}$, обладающих значительной ионной проводимостью, наблюдалась инверсия резонансного сигнала.

Исследование выполнено при финансовой поддержке Министерства образования и науки Российской Федерации (проект 10.1434.2017).

DOI: 10.21883/FTT.2019.03.47234.291

\section{1. Введение}

Импедансная спектроскопия изучает зависимость комплексной диэлектрической проницаемости (комплексной проводимости) от частоты. Импедансная спектроскопия (ИС) преимущественно развивалась как инструмент для электрохимических исследований; аппаратура и методы ИС изначально ориентированы на исследования явлений на границе фаз [1,2]. В отличие от оптической спектроскопии, изучающей энергетические состояния объектов микромира, импедансная спектроскопия, как правило, изучает свойства 2D-границ и макрообъектов, поэтому диапазон частот (энергий), в которых проводятся исследования, сдвинут в низкие частоты, типично - от десятков мегагерц до сотых долей герца.

В последние годы аппаратура и методы импедансной спектроскопии, достигшие высокой степени совершенства, все чаще применяются при исследованиях в физике твердого тела и других областях. Например, в [3] исследованы проводимость и диэлектрическая проницаемость в смешанных полупроводниковых кристаллах $\mathrm{Cd}_{0.8-x} \mathrm{~Pb}_{x} \mathrm{Zn}_{0.2} \mathrm{~S}$. В указанной работе использован наработанный в импедансной спектроскопии прием анализа данных по виду диаграммы Коула-Коула, что позволило надежно выделить вклад в суммарный импеданс от границ межкристаллитных зерен. (График Коула-Коула - параметрическая функция частоты $\left(X=Z^{\prime}(\omega) ; Y=-Z^{\prime \prime}(\omega)\right)$; величины мнимой и действительной частей импеданса откладываются по осям $Y, X)$. В [4] исследованы некоторые свойства кристаллов $\mathrm{LiIO}_{3}$. Среди других полученных результатов, также с использованием анализа диаграмм Коула-Коула (К-К), определен спектр времен релаксации, связанный с наличием ионной проводимости. В других работах с использова- нием ИС были определены температурные зависимости проводимости в кристаллах KDP [5-7].

Информация о параметрах комплексной проводимости исследуемых объектов, как правило, извлекается из обработки данных в широкой частотной области, что, помимо прочего, требует существенных затрат времени, в особенности на низкочастотном краю диапазона. Поэтому избыточной детализации спектров обычно избегают, выбирая соответствующий шаг сканирования частоты. Однако при этом могут быть упущены детали спектров, представляющие самостоятельный интерес.

\section{2. Исследовавшиеся образцы и методика эксперимента}

В работе исследовались образцы монокристаллов дигидроортофосфата калия (KDP) и йодата лития $\left(\alpha-\mathrm{LiIO}_{3}\right)$.

Монокристаллы дигидроортофосфата калия были получены из водного раствора изотермическим методом путем отбора конденсата растворителя при температуре $52^{\circ} \mathrm{C}$ с добавлением $1 \mathrm{ml} 1 \mathrm{M}$ раствора трилона-Б на 3 литра исходного раствора $\mathrm{KH}_{2} \mathrm{PO}_{4}$ для предотвращения выклинивания. В качестве исходного материала применялась соль $\mathrm{KH}_{2} \mathrm{PO}_{4}$ марки „осч.“. Полученные кристаллы имели правильную форму и бесцветную окраску. Рентгенофазовый анализ позволил определить параметры решетки $a=7.34 \AA, c=6.97 \AA$ и пространственную группу $I 42 d$, что соответствует результатам работ $[8,9]$. Образцы для исследований представляли собой квадратные пластины, вырезанные перпендикулярно направлению [001] и толщиной $1-3 \mathrm{~mm}$.

Монокристаллы йодата лития были выращены в виде бесцветных гексагональных призм. По результатам 


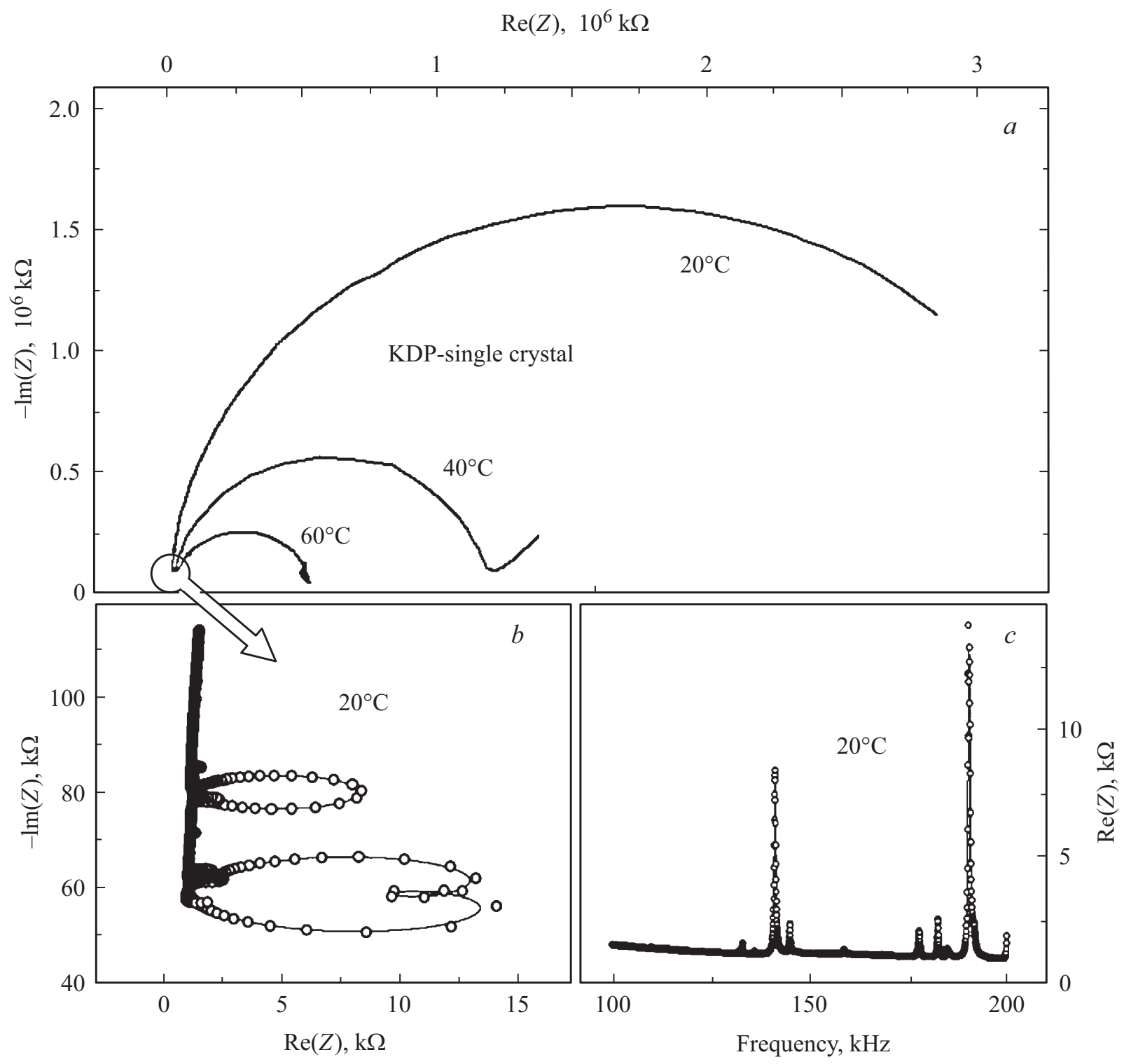

Рис. 1. $a-$ Комплексный импеданс в представлении Коула-Коула для монокристалла дигидрофосфата калия в широкой области частот при температурах $20,40,60^{\circ} \mathrm{C} . b-$ Та же зависимость того же образца в узкой области частот $135-200 \mathrm{kHz}$ при $20^{\circ} \mathrm{C}$. $c$ - Другое представление данных, показанных на рис. $1, b-$ зависимость $\operatorname{Re}(Z)$ от частоты в интервале частот $135-200 \mathrm{kHz}$.

рентгенофазового анализа выращенные кристаллы относятся к пространственной группе симметрии $P 6_{3} 2$ и имеют параметры ячейки $a=5.47 \AA$ и $c=5.16 \AA$, что находится в согласии с известными данными [10,11]. Монокристаллические образцы $\alpha$ - $\mathrm{LiIO}_{3}$ для исследований были вырезаны в виде шестигранных пластинок с плоскостями, перпендикулярными направлению [0001].

Импедансные спектры были получены на импедансметрах Novocontrol ALPHA-AN, Solatron 1260 и Elins Z2000 в частотном интервале от $1 \mathrm{~Hz}$ до $1 \mathrm{MHz}$ и также в более узких интервалах с амплитудой измерительного сигнала 1 В. Измерения проводились при комнатной температуре.

Рентгенофазовые исследования проводились на рентгеновском дифрактометре ARL X'TRA.

\section{3. Результаты экспериментов}

При исследовании импеданса некоторых объектов с высоким разрешением нами были обнаружены особенности, которые мы интерпретируем как проявление пьезоэлектрических резонансов в исследованных образцах.

На рис. 1 приведены графики зависимости комплексного импеданса монокристалла KDP от частоты. На рис. 1, $а$ приведены графики импеданса в широкой частотной области в представлении К-К. Для каждой температуры график имеет вид полуокружности; параметры окружностей меняются с изменением температуры. Хорошо известно, что график К-К в виде полуокружности отвечает параллельно соединенным сопротивлению и емкости [2]; в нашем случае - это геометрическая 

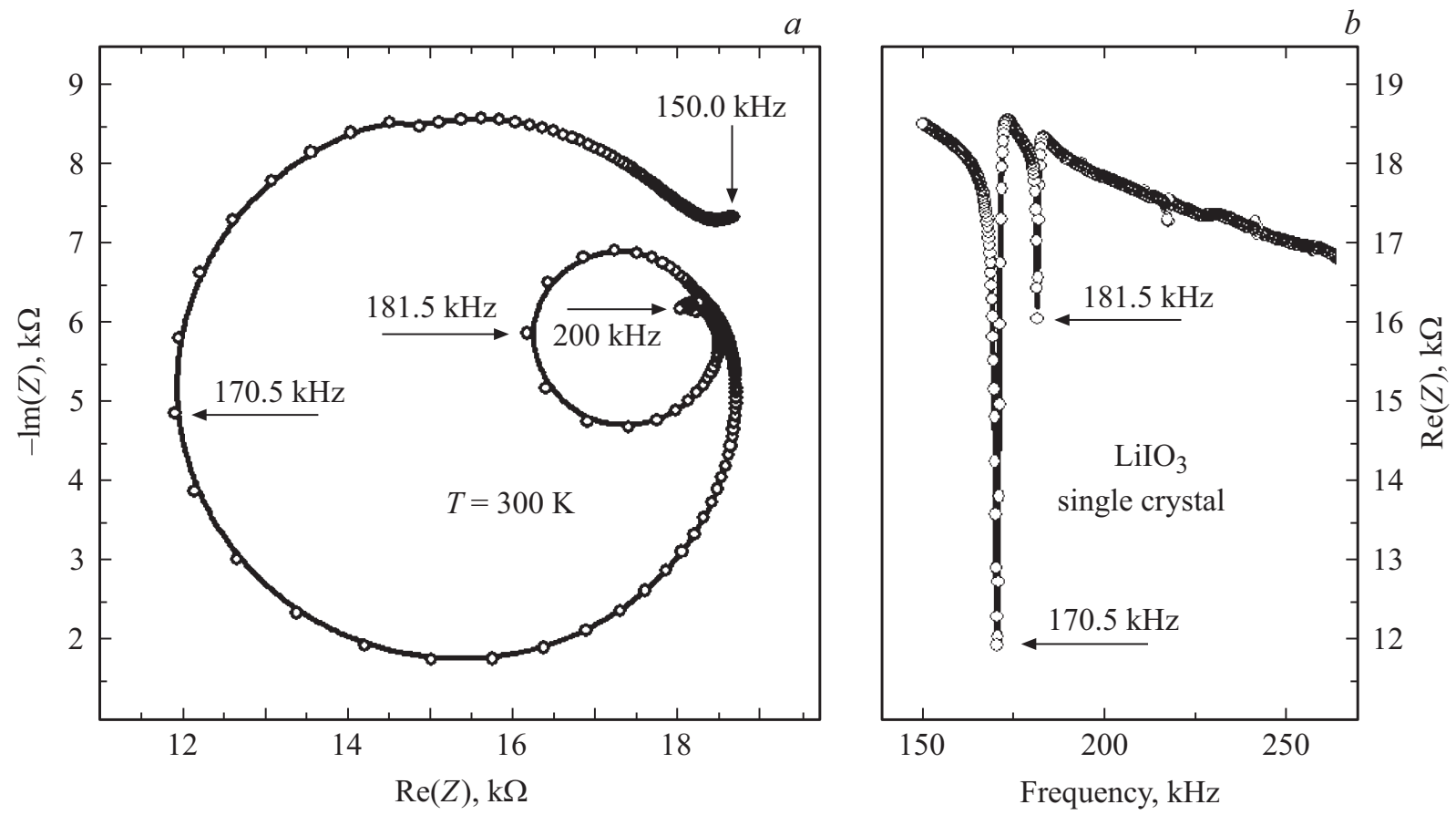

Рис. 2. $a$ - Годограф комплексного импеданса кристалла $\alpha-\mathrm{LiIO}_{3}$ в области пьезоакустического резонанса (частоты $150-200 \mathrm{kHz}$ ), комнатная температура. $b$ - зависимость активной составляющей импеданса от частоты (данные того же эксперимента, что и на рис. $2, a)$.

емкость и сопротивление образца. Видно, что на графике импеданса в широкой области частот $(1, a)$ резонансные эффекты не различимы.

Результаты экспериментов с высоким разрешением по частоте выявляют наличие резонансов в высокочастотной области. На рис. $1, b$ и $1, c$ показан импедансный спектр того же образца в области $100-200 \mathrm{kHz}$. На рис. $1, b$ график показан в представлении К-К, на рис. 1, $c$ показана зависимость активной составляющей импеданса от частоты в той же области частот, что и на рис. $1, b$. В спектрах, снятых с высоким разрешением, явно проявляются особенности резонансного характера. Характер полученных зависимостей будет обсужден далее.

На рис. 2 приведены полученные экспериментально импедансные спектры монокристалла $\alpha-\mathrm{LiIO}_{3}$ в области частот $150-260 \mathrm{kHz}$, также содержащие особенности резонансного характера. Однако активная составляющая импеданса на этих кривых в области резонанса уменьшается, что принципиально отличается от разобранного выше случая кристалла KDP. Одно из возможных объяснений этого отличия приведено ниже.

\section{4. Обсуждение результатов}

Общий ход представленных графиков для кристаллов KDP понятен. Кристалл вне резонансов можно представлять емкостью, подключенной параллельно с очень большим сопротивлением. В области высоких частот (левый край полуокружности) импеданс определяется емкостью. Импеданс емкости в представлении К-К должен представлять вертикальную прямую $(Z=1 / i \omega C)$. В высокочастотной области, на левых краях полуокружностей, график импеданса ведет себя подобным образом (за исключением окрестностей резонанса).

Вблизи резонанса амплитуда механических колебаний должна возрастать, и вместе с этим должна возрастать диссипация энергии. На графике $Z^{\prime}(f)$ проявление диссипации отображается появлением активной составляющей $Z^{\prime}$. График К-К отходит от вертикальной прямой в сторону положительных значений оси $Z^{\prime}$. Годограф импеданса в области резонанса в координатах К-К подобен годографам любой колебательной системы в области резонанса и представляет собой окружность около резонансной частоты.

Следует отметить, что предложенная интерпретация не столь очевидна, как может показаться. Кристалл KDP обладает высоким сопротивлением, и, следовательно, рассеивает относительно малую часть мощности внешнего источника (переменного) тока. Возникновение механических колебаний в резонансе должно сопровождаться дополнительной диссипацией энергии, что, в свою очередь, должно „восприниматься“ внешней цепью как уменьшение сопротивления. Однако в эксперименте (особенно видно на рис. 1,c) в области резонанса годограф идет в сторону больших значений оси $\operatorname{Re}(Z)$, что соответствует увеличению сопротивления, аналогично тому, как в случае резонанса в параллельном $L C$ контуре.

Кажущееся противоречие разрешается при анализе того, как осуществляются импедансные измерения. Что- 
бы понять ход графика, нужно пересчитать параллельное сопротивление цепи в последовательное.

Две схемы эквиваленты, если мнимые и действительные части импеданса двух схем равны. Обозначим через $R_{s}$ и $C_{s}$ сопротивление и емкость последовательной схемы, эквивалентной кристаллу, а через $R_{p}$ и $C_{p}-$ сопротивление и емкость того же кристалла при параллельном представлении. Расчет по обычным правилам дает

$$
R_{s}=R_{p} /\left(\omega^{2} C_{p}^{2}\left(R_{p}^{2}-1 / \omega^{2} C_{p}^{2}\right)\right) .
$$

Из формулы видно, что для образца с высоким сопротивлением

$$
\text { (при } \left.R_{p} \gg 1 / \omega C_{p}\right)
$$

с увеличением сопротивления образца $\left(R_{p}\right)$ эквивалентное последовательное сопротивление $\left(R_{S}\right)$ уменьшается, что и приводит к увеличению тока и бо́льшей диссипации энергии.

Отметим также, что в представлении $\mathrm{K}-\mathrm{K}$ (рис. $1, b)$ виден дублетный характер линии резонанса на частоте $189 \mathrm{kHz}$, тогда как при обычном представлении тех же данных $Z^{\prime}(f)$ дублетный характер (при том же разрешении по частоте) практически не заметен (рис. $1, c$ ).

В реальных кристаллах, размеры которых близки по разным направлениям, особенно при наличии вицинальных граней или внутренних границ, могут возбуждаться связанные резонансы, что будет приводить к графикам достаточно сложного вида. Экспериментально регистрируемые спектры К-К в этом случае содержали множество накладывающихся петель. Это может быть использовано при диагностике качества кристаллов.

В случае иодида лития интерпретация резонансных особенностей на импедансных кривых менее очевидна. Могут быть высказаны качественные соображения по поводу существенного отличия вида резонансных кривых в этом материале от зависимостей для KDP.

Кристалл $\alpha-\mathrm{LiIO}_{3}$ обладает заметной проводимостью по ионам $\mathrm{Li}$, и условие (2) для него может не выполняться. В случае, если будет иметь место соотношение, обратное к (2), тогда ток через образец в основном будет определять мнимая составляющая импеданса. Из формулы (1) при этом будет следовать, что зависимость $R_{s}$ и $R_{p}$ от частоты синбатна. Падение импеданса в резонансе в этом случае аналогично последовательному резонансу в $L C$ контуре. При этом параллельный резонанс шунтируется высокой проводимостью образца и не проявляется в экспериментально регистрируемых спектрах.

\section{5. Заключение}

Таким образом, в работе впервые наблюдались резонансные особенности импедансных спектров материалов с пьезоэлектрическими свойствами и предложена их интерпретация.

Авторы выражают благодарность Л.Н. Рашковичу за любезно предоставленные монокристаллы KDP и $\alpha$-LiIO3.

\section{Список литературы}

[1] Impedance Spectroscopy Theory, Experiment and Applicaions / Eds J. Barsoukov, R. Macdonald. 2nd ed. Willey-Interscience. $595 \mathrm{p}$.

[2] Moden Aspects of Electrochemestry no.32 / Eds B.E. Conway, J.O’M. Bockris, R.E. White. Kluwer Academic Publishers, $420 \mathrm{p}$.

[3] T. Shekharam, R.V. Laxminarasimha, G. Yellaiah, T. Mohan Kumar, M. Nagabhushaman. J. Alloys \& Comp. 617, 952 (2014).

[4] А.Л. Пирозерский, Е.В. Чарная, В.Г. Залесский, Е.Л. Лебедева, К.В. Филипов. ФТТ 51, 670 (2009).

[5] R.H. Chen, Chen-Chieh Yen, C.S. Shern, T. Fukami. Solid State Ionics 177, 2857 (2006).

[6] Jong-Ho Park. Solid State Commun. 123, 291 (2002).

[7] S.V. Grabovsky, I.V. Shnaidshtein, B.A. Strukov, Y. Uesu, M. Fukunaga. Ferroelectrics 397, 90 (2010).

[8] G.M. Meyer, C. Vettier, R.J. Nelmes. J. Phys. C 13, 4035 (1980).

[9] R.J. Nelmes, Z. Tun, W.F. Kuhs. Ferroelectrics 71, 125 (1987).

[10] С.А. Бутолин, Л.Ф. Белова, Н.М. Иванова, Р.Н. Самойлова, О.М. Котенко, И.М. Докучаева. Изв. АН СССР. Неорган. материалы 11, 862 (1975).

[11] J.L. de Boer, F. van Bolhuis, R. Olthof-Hazekamp, A. Vos. Acta Crystallographica 21, 841 (1966).

Редактор К.В. Емцев 